\title{
Oceanographic Instrument Returns After Two Years
}

\author{
By David Hebert and Tom Rossby
}

\section{IN EARLY JANUARY 2003, 92} subsurface isopycnal RAFOS floats were loaded on a truck for the start of a long voyage. The floats were delivered to Fort Pierce, Florida and loaded on the R/V Seward Johnson II at the Harbor Branch Oceanographic Institution. In March, Drs. Hebert and Rossby started on a month-long expedition from the Canary Islands to deploy these floats south of the Cape Verde Islands. The goal of this project, the Lagrangian Isopycnal Disper- sion Experiment (LIDEX), funded by the National Science Foundation, is to determine the processes that mix the waters in the ocean horizontally (along constant density surfaces) and at what rate. When these scientists departed from the Canary Islands to deploy the floats, little did they know that one of their floats would eventually be returned by a fisherman.

Mixing in the ocean is separated into two components: diapycnal and isopycnal (i.e., across and along density

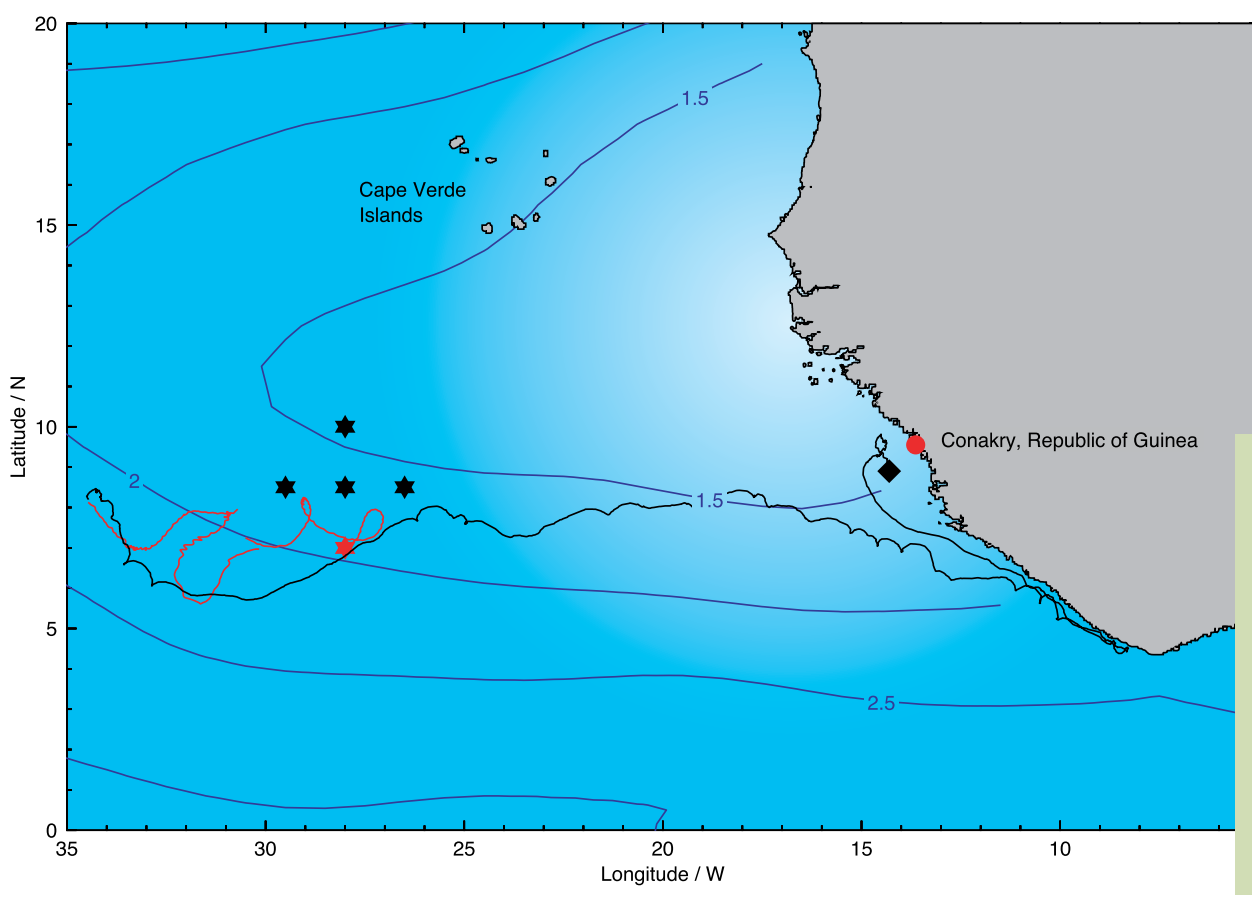

surfaces, respectively). In the last few years, significant effort has been made to determine the processes responsible for diapycnal mixing in the ocean's interior, and now these processes are known. However, the stirring and mixing of water along isopycnals is poorly understood, and even the use of the terms "stirring" and "mixing" depends on the horizontal scales that are being resolved. The effective isopycnal eddy diffusivity is generally believed to be scale-dependent (i.e., process-dependent). Models currently used for climate studies cannot resolve the mesoscale eddies and submesoscale mixing processes because the grid size they use in their models is larger than the size of a mesoscale eddy (tens to hundreds of kilometers across). Thus, the fluxes by these eddies must be represented in terms of quantities resolved by the models (i.e., parameterized). To date,

Figure 1. Clusters of isopycnal RAFOS floats were deployed at five locations (stars) and at two depths in March and April 2003. The trajectory of one isopycnal RAFOS float (\#329) is shown while underwater (red line) and on the surface (black line), and at deployment location off of northwestern Africa (red star). The blue contours show the mean dissolved oxygen concentration at $500 \mathrm{~m}$ depth. This float was recovered (black diamond) by a local fisherman, taken the U.S. Embassy in Guinea (red circle), and returned to the University of Rhode Island. 
there is a lack of good field observations to test any eddy flux parameterizations. In LIDEX, the processes and dynamics of dispersion on isopycnal surfaces on scales from several kilometers to hundreds of kilometers will be examined. These data will significantly improve ocean models.

Clusters of isopycnal RAFOS floats were deployed at five locations and on two density surfaces in the low-oxygen tongue off of northwest Africa (Figure 1). The nominal depths of the density surfaces were $500 \mathrm{~m}$ and $800 \mathrm{~m}$. The floats were to remain underwater for nearly two years. All of the floats measure pressure and temperature every six hours. The 50 floats on the shallower density surface measured dissolved oxygen using the new Aanderaa Optode sensor. The location of each float is determined every six hours by triangulation using sound sources. The data are sent back to the laboratory through the Argos satellite system (for more information go to http://noaasis.noaa.gov/ARGOS/ and http://www.argosinc.com/) after the float surfaces at the end of its mission. Thus, estimates of the isopycnal fluxes of temperature and oxygen can be made after all the data are received.

The study area off of northwestern Africa (Figure 1) was chosen for two reasons. First, the mean currents in the region are weak. Thus, the floats should

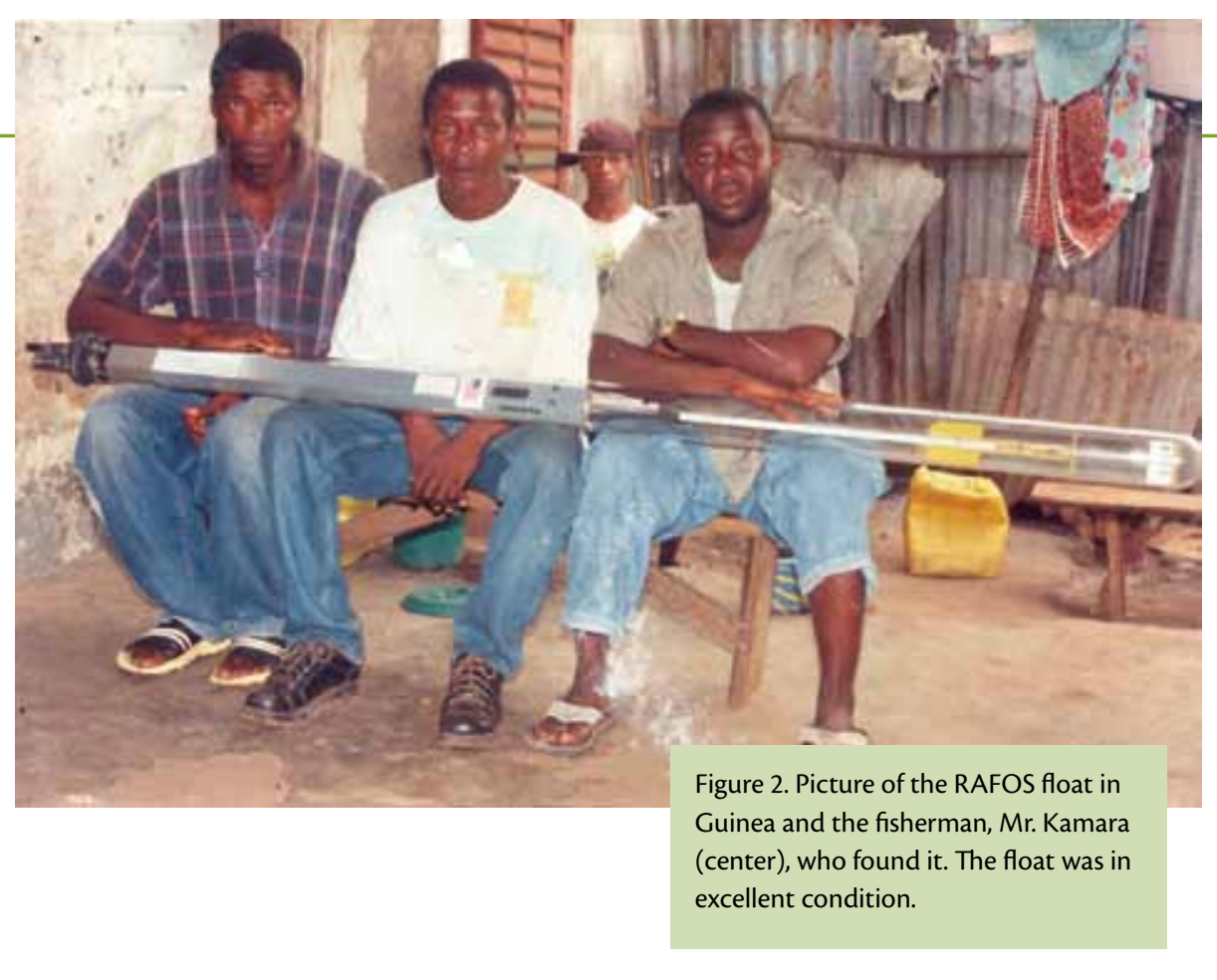

remain in the region for their two-year mission. Second, the mean dissolved oxygen concentration isopleths (blue contours in Figure 1) are not parallel to the mean isotherms, which are mainly zonal. The low-oxygen tongue off northwestern Africa is due to both isolation of the water from the surface and enhanced productivity and organic regeneration in the coastal upwelling zone off North Africa. It is believed that the low-oxygen water is advected westward from the coastal upwelling sites. With this assumption, and the fact that the dissolved oxygen concentration is increasing to the west, only isopycnal and diapycnal mixing of higher-oxygenated waters can be responsible for the observed dissolved oxygen concentration horizontal structure. This description assumes a mean westward zonal current, which has not been conclusively proven. The direction of the weak circulation in this region is not known. The mean movement of the floats can answer this question.

One of the floats that was deployed at $7^{\circ} \mathrm{N}, 28^{\circ} \mathrm{W}$ on April 6, 2003 (red star in Figure 1) surfaced prematurely. This float remained underwater for 420 days before surfacing. While underwater, its position was determined from acoustic beacons (red track) every six hours. The float moved slowly westward while making large looping motions due to eddies that stir the ocean. While at the surface, the location of the float was determined from the Argos satellites (black line in Figure 1). During the 185 days on the ocean surface, surface currents carried the float eastward to Africa, down along the coast, and then back northwards along the coast off of the Republic of Guinea (black diamond). At that location, a local fisherman, Mr. Osman Kamara, found the float (Figure 2). He brought it to Conakry, Guinea (red circle 


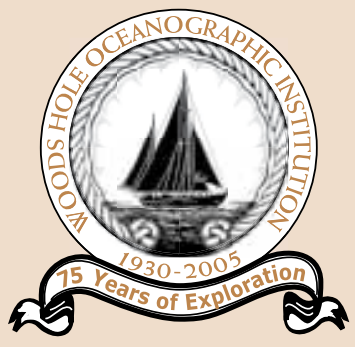

Celebrating 75 years of ocean research, education, and exploration

\section{Woods Hole}

\section{OCEANOGRAPHIC}

\section{INSTITUTION}

announces an

anniversary symposium

September 20-22, 2005

Woods Hole, Massachusetts

Twenty-six speakers representing fifteen organizations will discuss six themes:

Air-Sea Exchange

Climate Change

Life in the Ocean

Mid-Ocean Ridges

Observing the Ocean

Ocean Circulation

The opening social will feature a story-telling session

Information and Registration at: www.whoi.edu/75tb/schedule in Figure 1), the country's capital.

Although the actual recovery of the floats is not critical or expected, it is often useful to see how well the floats survive after being underwater for long periods. Thus, contact information is included within each float. Mr. Kamara contacted Dr. Hebert in order to return the float to Rhode Island. After several telephone calls during the Thanksgiving holiday period, it was not clear how to send Mr. Kamara a box for the float and pay for the shipping charges. Dr. Hebert convinced Mr. Kamara to deliver the float to the U.S. Embassy in Conakry. A box for the float could be shipped to the Embassy. Although wary of trying to deliver such a strange item to an embassy in Africa, Mr. Kamara did just that. With the assistance of Special Agent Daniel Wilhelm and the Embassy staff in Conakry, the float was return to Rhode Island at the end of January, a little more than
Figure 3. Picture of the RAFOS float after its return to University of Rhode Island to Professors Hebert and Rossby. two years since it left the state. The float was in excellent condition (Figure 3). Drs. Hebert and Rossby appreciate the assistance of Mr. Kamara and the Embassy in returning this instrument.

This float was one of those equipped with the novel oxygen sensor from Aanderaa. The return of the instrument allowed them and us to assess how well the sensor fared from prolonged exposure in the ocean and to see how much biological fouling occurred. Visual inspection of the float and the sensor suggests only modest fouling took place during its half-year drift on the surface in nearequatorial waters. 四

David Hebert (david.hebert@uriedu) is Professor, Graduate School of Oceanography, University of Rhode Island, Narragansett, RI, USA. Tom Rossby is Professor, Graduate School of Oceanography, University of Rhode Island, Narragansett, RI, USA. 